Dementia

\section{Standing at the crossroads: which way will dementia services evolve?}

R Bullock

\section{Fundamental shifts now need to occur to get the right services to the patients and their carers.}

$\mathrm{T}$ he provision of services for people suffering with dementia in the UK has reached an important crossroads. In reality, no dedicated services exist, with the work being primarily undertaken by old age psychiatrists; with a smaller percentage performed by geriatricians and a minority by neurology. The reason for this distribution was that historically the main requirement was managing Alzheimer's disease (AD); which before the introduction of cholinesterase inhibitor treatment in 1997 usually presented in the latter stages, predominantly with behavioural symptoms-reinforcing both the psychiatric emphasis and nihilistic attitudes to intervention. Younger patients and rarer dementias were the province of the neurologists, who offered a diagnostic service; while geriatricians managed cognitive impairment in relation to other physical comorbidities.

Since 1997, memory clinics have rapidly evolved, a direction reinforced in the 2001 National Service Framework for Older People (NSF). ${ }^{1}$ Again, most clinics tend to be in psychiatric services and continue to concentrate on $\mathrm{AD}$. However, it is increasingly recognised that dementia involves more than $\mathrm{AD}$; with particularly, cerebrovascular disease playing an increasing part in the causation and management of many forms of cognitive impairment-lending the memory clinics a more "medical" feel, while at the same time, stroke services begin to look at cognitive as well as physical assessments. Conversely, the fact that Parkinson's disease (PD) is associated with more severe cholinergic impairments than $\mathrm{AD}$, and that these patients have a high rate of dementia, has led to a traditional medical preserve having to become more "psychiatric". Now that a cholinesterase inhibitor has been shown to help in PD dementia, ${ }^{2}$ who will prescribe what and when will hopefully help focus the long awaited clarification of some of these issues.

What is clear is that fundamental shifts now need to occur to get the right services to the patients and their carers. The first shift is to accept that dementia is actually a medical condition that has psychiatric consequences. It is one of the most expensive medical conditions, estimated at costing around $£ 8$ billion a year to the statutory services, ${ }^{3}$ even before the carers contribution is considered-yet has no service framework of its own, nor even an accurate understanding of what resources are actually spent on it. For example, it is stated that two thirds of acute hospital admissions are over 65 years old, and half of those have a psychiatric disorder, yet acute hospitals do not consider this their work. Instead, rudimentary old age meet a huge demand and the introduction of reimbursement charges reinforces the hospital view. Clearly dementia must be included as part of the overall range of older people's services, which is what the NSF tries to address. Future commissioning strategies need to reflect this; as currently one of the most expensive conditions in the NHS is being almost exclusively funded out of one of the poorest resourced specialties.

The solution is not more money though-the resource probably lies within the current systems. The major problem is that currently, any hint of dementia means a referral to the local psychiatric service. Provision of care thus seems to be universally diagnosis rather than needs led. The social services document "Fairer Access", 4 delineates the work load into low, moderate, substantial, and critical levels of priority. The onus for specialist intervention is rightly on critical and substantial work, with the more generic workers managing the low and moderate workdiagnosis is not an issue. The very presence of old age psychiatry has performed a valuable service to patients and carers, but in doing so has inadvertently deskilled many other health and social care workers. They now see any dementia as needing specialist help. This is not the case; and future strategies need to highlight the training of psychiatry liaison services struggle to existing primary and acute services to manage the less complex cases.

To some extent the memory clinics run by geriatricians and neurologists are doing this; and with new and more beneficial pharmaceutical treatments emerging, these will undoubtedly get more common. However, recognising and managing the less complex cognitive impairments in the wider acute hospital definitely needs more attention. Perhaps the major need remains in the community, where old age psychiatry has its largest presence. Here again, primary care services, including district nursing and health visitors should be trained to handle low and moderate level dementia without the need for specialist intervention. This is no different to the scenario in any other chronic disorder. Another anachronism is that geriatricians seem rarely able to access the community mental health teams directly, but this could be easier should older people's services unify. Should this take place in the primary care trusts (PCTs), then a simple organisational shift may help create the necessary functional solution-especially if they were to become care trusts and unite social care as well.

It does mean that the next fundamental shift is that old age psychiatry needs to leave the mental health trusts, where it is often the poor relation, and become part of dedicated older people's services-wherever they reside. This is more in keeping with Europe (where old age psychiatry is not a recognised specialty as such) and has a precedent in the UK with child psychiatry, where in many areas it has already joined paediatrics. An alternative to moving to the PCT may be a move to social services-similar to the Learning Difficulties model or that found in older people's services in Scandinavia. Either would also make it easier for patients to access intermediate care-something that mental health patients are often short sightedly excluded from in many areas.

New dementia services must therefore be re-commissioned across the existing health and social care system, working towards the NSF statement that "specialist services should support primary care services in looking after their patients" - rather than taking on the complete care provision. Isolating mental health, which has unfortunately been perpetuated by giving it its own standard in the older person's NSF, cannot continue. Failure to achieve this will overburden existing specialist provision and increase waiting lists and unnecessary admissions to the acute sector. The systemic approach must also apply to the social care sector, 
particularly the care standards and social care inspectorate who currently have a very proscriptive and diagnosis led approach to managing the nursing home population. In reality most nursing homes are "dementia homes" to one degree or another and to pretend otherwise is a folly. Suggesting that all AD and other dementia always needs specialist provision is wrong and is making this aspect of delivery of care cumbersome and unnecessarily expensive.

Care pathways ${ }^{5}$ and collaboratives have been attempted to bring all these disparate services together for people with dementia; but they remain as good as their weakest link, where unilateral decisions can be destabilising. They also usually offer what is available rather than sometimes what is needed-creativity is often diluted across organisational boundaries. Involving people in choosing their own care, perhaps through the use of direct payments and creating menus of available options, including the voluntary sector provision, may radically change current spending patterns. The final fundamental shift is therefore to move away from the current paternalistic reliance on services having to take over the care of people with dementia to a choice agenda where specialist and non-specialist providers offer the right menu of services to support the continued independence of the person with dementia and their carer at home.
Public commissioning may seem a radical move, but may be an adjunct to the impending practice based commissioning and payment by results. Old age psychiatry should not feel threatened; it has already seen its work change dramatically over the past seven years. What is now needed is an emphasis on sharing its skills with others to help destigmatise the diagnosis of dementia and manage the numbers of patients who continue to present with earlier cognitive impairment. Making cognition an important part of all branches of medicine will have large potential benefits-for example, effective treatment of hypertension in mid-life and beyond can reduce the incidence of dementia by up to a fifth and treatment of most cardiac risk factors through life has a beneficial effect on the brain. Cardiologists should be aware of this. It is also known that a third of people after a stroke, $40 \%$ of people with PD, and $70 \%$ of people with significant memory disturbances go on to develop a dementia, and have, by definition become known to services long before that. This gives opportunities for preventative work in primary and secondary care, managed through disease registries-again, as occurs in other chronic diseases.

Public education about risk factors and the benefits of keeping mentally and physically fit should accompany such a health promotion strategy. To some extent, people can help delay their "brain failure" if properly informed. Thus, this mainstreaming of dementia into medicine and on into increased public awareness has to be the primary aim for those working in the field of old age psychiatry over the next decade. This will help the older population through making dementia a recognised condition, which they can do something about, in the same vein as diabetes and heart disease; and assist old age psychiatrists in realising their particular specialism more effectively, and align it with their ever changing work load.

Postgrad Med J 2005;81:731-732.

doi: 10.1136/pgmj.2005.033563

Correspondence to: Dr R Bullock, Kingshill Research Centre, Victoria Hospital, Okus Road, Swindon SN1 5HZ, UK; roger.bullock@

kingshill-research.org

Funding: none.

Conflicts of interest: none.

\section{REFERENCES}

1 Department of Health. Older peoples national service framework. London: HMSO, 2001.

2 Emre M, Aarsland D, Albanese A, et al. Rivastigmine for dementia associated with Parkinson's disease. NEJM 2004;351:24.

3 Bosenquet N, May J, Johnson N. Alzheimers disease in the UK: burden of disease and future care. Health Policy Review Number 12. London: Imperial College of Science and Technology, 1998.

4 Department of Health. Fairer access to care services. London: HMSO, 2002.

5 Naidoo M, Bullock R. An integrated care pathway for dementia. London: Harcourt, 2001.

\section{"Leaving town" versus "taking leave": the case for re-thinking academic leave restrictions}

\section{R J Epstein}

\section{Today's knowledge worker will be judged by achievement rather than attendance.}

A cademic institutions permit staff to take non-vacation leavevariously categorised as conference leave, study leave, training leave, special leave, etc-with the aim of adding long term value to the institution. ${ }^{1}$ Logically, such value-adding leave should be considered an intangible asset, rather than a cost, of the institution. Yet most employers continue to offer academic leave as a restricted "perk" or privilege, implying that the institution (a) cannot judge the value of individual leave applications, and (b) tacitly approves staff not working while on leave.

The pressures of globalisation are now highlighting this anomaly. In the past few decades the scope of day to day academic activities has extended to the regional and international sphere; this diffusion of the academic workplace away from its historical lecture theatre roots is part of a broader migration away from institutional imperialism ${ }^{2}$ and towards outsourcing, offshoring, flexitime, portfolio careers, and telecommuting. ${ }^{3-5} \mathrm{New}$ communication technologies mean that "out of town" is no longer synonymous with "off duty"-many academics no longer live monkish existences confined to ivory towers, but rather pursue an executive style 24/7 work schedule pursuing opportunities in diverse locations while remaining in contact with the primary workplace through email, internet, and hand phone. An absent medical academic (for example, attending an overseas meeting) can spend a large proportion of each conference day responding to phone inquiries from junior clinical staff, replying to faxed queries about patients, studying emailed data from lab researchers, completing manuscripts, etc. Indeed, as the communications revolution continues to gain speed, one increasingly hears the comment that the most efficient way to get work completed is to go away. 
Administrative adaptation to this technology driven change in the workplace has been slow in many institutions, ${ }^{6}$ reflecting the prioritisation of bureaucratic process over academic productivity first noted by Sonnenberg. ${ }^{7}$ Academia now finds itself squeezed between this historical drift towards overadministration and the growing pressures towards corporatisation ${ }^{8}$; at a time when clinical academic careers are becoming less attractive, ${ }^{9}$ this state of affairs merits concern. Moreover, from the competitive standpoint of the university, the natural tendency of the bureaucracy to control academics by mandating on-site attendance makes about as much sense as restricting the number of grant applications or publications that each faculty member is permitted to produce.

One may well ask: why should the system of leave regulation for academics differ so fundamentally from that of "clock-on, clock-off" occupational categories such as bus drivers and soldiers? Firstly, service work of the latter kind can be characterised as dissipativewhen the shift is finished, the work for that period must also be finishedwhereas academic work (completing reports, filing assessments, marking theses, preparing talks, revising articles, etc) is cumulative, piling up in the intray during staff absences. Secondly, academic productivity often depends upon creativity, a staff resource that is all too often stifled by managerial drives towards tight control $^{10}$; hence, a restricted leave system may redirect staff ingenuity to maximising bureaucratic "leave niches" of all categories, rather than producing more internationally competitive outputs. At the other extreme, abolition of leave restrictions would not mean that each staff is entitled to unlimited leave; in contrast, it would mean that leave as an automatic entitlement (that is, akin to annual leave) has also been abolished.

We have entered an unfamiliar era in which work productivity is more effectively enhanced by dynamism and mobility than by remaining obediently chained to the office desk. In the worst case scenario, where a staff misuses leave in the long term, the resulting lack of productivity should provide grounds for contract non-renewal-or, in the case of tenured staff, for withdrawal of resources. As today's knowledge worker will be judged by achievement rather than by attendance, they will be better motivated by incentives for entrepreneurialism than by deterrent regulations and penalties. ${ }^{11}$

The "hidden curriculum" of medicine has been defined as the less explicit administrative framework-institutional policies, evaluation procedures, resource allocation decisions-of the learning environment. ${ }^{12} \mathrm{~A}$ one-size-fitsall mentality is attractive to administrators, but anathema to academics; traditional contracts have emphasised control rather than performance, but globalisation has created a new intensity of competition that is incompatible with the top heavy bureaucratic dominance of yesteryear. The modern tertiary institution now has both the opportunity and obligation to focus its energies on productivity challenges more serious than that of monitoring staff movements. However, this will require the political will to abandon ancient geographical notions of what constitutes "leave" and, instead, to encourage staff to risk and innovate wherever possible.

Postgrad Med J 2005;81:732-733.

doi: $10.1136 /$ pgmi.2005.038232

Correspondence to: Professor R J Epstein, Room 404, Professorial Block, Department of Medicine, University of Hong Kong, Queen Mary Hospital, Pokfulam Road, Hong Kong; repstein@hku.hk

Funding: none.

Competing interests: none declared.

\section{REFERENCES}

1 Bennett JR. Consultants' study leave-value for money? Postgrad Med J 1997;73:32-4.

2 Prahalad CK, Lieberthal K. The end of corporate imperialism. Harv Bus Rev 2003:81:109-17.

3 Rosow JM, Zager R. Punch out the time clocks. Harv Bus Rev 1983;61:12-16.

4 Polanyi M, Tompa E, Rethinking work-health models for the new economy: a qualitiative analysis of emerging dimensions of work. Work 2004; 23:3-18.

5 Apgar M. The alternative workplace: changing where and how people work. Harv Bus Rev 1998;76:121-36.

6 Ulrich D, A new mandate for human resources. Harv Bus Rev 1998;76:124-34.

7 Sonnenberg A. Process and accomplishment in academic medicine. Med Hypotheses 2004:62:1006-11.

8 Miller S, Academic autonomy. In: Coady T, ed. Why universities matter. Sydney: Allen and Unwin, 2000.

9 Goldacre M, Stear S, Richards R, et al. Junior doctors' views about careers in academic medicine. Med Educ 1999;33:318-26,

10 Amabile TM. How to kill creativity. Harv Bus Rev 1998;76:76-87.

11 Souba WW. New ways of understanding and accomplishing leadership in academic medicine. J Surg Res 2004;117:177-86.

12 Hafferty FW. Beyond curriculum reform: confronting medicine's hidden curriculum. Acad Med 1998;73:403-7.

13 Coleridge ST, Smith-Barbaro P, Knisley C. A practical method for increasing scholarly activity in an academic family medicine department. Teach Learn Med 2004;16:181-5.

14 Tarquinio GT, et al. Effects of performance-based compensation and faculty track on the clinical activity, research portfolio, and teaching mission of a large academic deparment of medicine. Acad Med 2003;78:690-701. 